\title{
Binary interest rate sensitivities of emerging market corporate bonds
}

\section{Mariya Gubareva \& Maria Rosa Borges}

To cite this article: Mariya Gubareva \& Maria Rosa Borges (2017): Binary interest rate sensitivities of emerging market corporate bonds, The European Journal of Finance, DOI: 10.1080/1351847X.2017.1400452

To link to this article: http://dx.doi.org/10.1080/1351847X.2017.1400452

$$
\text { 曲 Published online: } 16 \text { Nov } 2017 .
$$

Submit your article to this journal

Q View related articles $\longleftarrow$

View Crossmark data $\asymp$ 


\title{
Binary interest rate sensitivities of emerging market corporate bonds
}

\author{
Mariya Gubareva (D) ${ }^{\mathrm{a}, \mathrm{b}, \mathrm{c}, \mathrm{d}}$ and Maria Rosa Borges (D) ${ }^{\mathrm{b}, \mathrm{e} *}$ \\ ${ }^{a}$ ISCAL - Lisbon Accounting and Business School, Instituto Politécnico de Lisboa, Lisbon, Portugal ${ }^{b}$ ISEG - Lisbon \\ School of Economics and Management, Universidade de Lisboa, Lisbon, Portugal ${ }^{c}$ SOCIUS - Research Centre in \\ Economic and Organizational Sociology, Universidade de Lisboa, Lisbon, Portugal ${ }^{d}$ CSG - Research in Social \\ Sciences and Management, Universidade de Lisboa, Lisbon, Portugal ${ }^{e}$ UECE - Research Unit on Complexity and \\ Economics, Universidade de Lisboa, Lisbon, Portugal
}

(Received 13 November 2016; final version received 4 October 2017)

\begin{abstract}
We develop a framework to assess interest rate sensitivities of emerging market corporate debt. Our analysis, based on yield indexes, is applied to investment grade and high yield portfolios. We reach beyond correlation-based analyses of interest rate sensitivity and keep our scope centered at capital gains of emerging market corporates and U.S. government bonds portfolios. Our empirical analysis spans over the period 2002-2015. We address interest rate sensitivity of assets during the ignition, apogee, and the aftermath of the global financial crisis. Based on historical data series, we evidence that the emerging market corporate bonds exhibit two different regimes of sensitivity to interest rate changes. We observe switching from a positive sensitivity under the normal market conditions to a negative one during distressed phases of business cycles and provide economical explanations of such phenomena. We show that emerging market corporate bonds, which on average could appear rather insensitive to the interest rate risk, in fact, present binary interest rate sensitivities. This research sheds light on how financial institutions may approach interest rate risk management including the downside risk hedge. Our findings allow banks and financial institutions to optimize economic capital under Basel III regulatory capital rules.
\end{abstract}

Keywords: Fixed income; portfolio performance evaluation; downside risk management; emerging markets; corporate debt; interest rate sensitivity

\section{Introduction}

The likelihood that the U.S. Federal Reserve will raise interest rates exercises unprecedented pressure on the global financial system. Financial institutions all over the world face a number of challenges, which place a significant strain on their profitability and capital adequacy levels. Not surprisingly, there is a growing volume of scientific research addressing the effects of interest rate changes on bank performance and solvency. See, for example, Berends et al. (2013), Neal et al. (2015), Dupoyet, Jiang, and Zhang (2016), Gubareva and Borges (2016), Gubareva and Borges (2017), and references therein.

On the other hand, the regulatory bodies try to create a widespread awareness for the possible negative impacts of interest rate (IR) changes on bank balance sheets and profitability; see, for example, the recent document entitled 'Interest rate in the banking book' by BCBS (2016) proposing changes to the regulatory capital treatment and supervision of Interest Rate Risk in Banking Book (IRRBB).

\footnotetext{
*Corresponding author. Email: mrborges@iseg.ulisboa.pt
} 
The above-mentioned document (BCBS 2016) outlines possible effects of IR increases, including changes to net interest margins, balance sheet structure, and values of IR-sensitive assets and liabilities. At this point, it becomes especially important to correctly assess the IR sensitivity of assets, which is a measure of how much the price of a fixed-income asset will vary as a result of changes in the interest rate environment. The more the price varies, the more sensitive to IR the asset is. But, what is really important for managing IRRBB is how the prices of assets react on medium-term trends in IR dynamics.

Nevertheless, the IR sensitivity of corporate debt is traditionally analyzed in terms of yield sensitivity of corporate bonds to changes in the yield curve of risk-free assets (see Manzoni 2002; Boulkeroua and Stark 2010, 2013). So, the IR-induced impacts in the price of assets are obfuscated as researchers main interests are centered on the interest rate - credit spread relationship, and not on the net present value of fixed-income portfolios.

The distinctive feature of our work is that we address the capital gains, from the point of view of medium-term investment in the banking book, and not from an instantaneous trading book perspective. We use the term capital gain solely for the difference between the final price of the portfolio and its initial price, not accounting for interim coupon payments.

The novelty of our approach resides in the medium run capital gain analysis, as opposed to the studies of daily changes in interest rates and credit spreads, with posterior averaging of daily statistics series over extended time intervals in order to come up with a kind of average spreadyield or yield-yield IR sensitivities of assets. Our results contrast with many quantitative and qualitative findings of previous research (see Boulkeroua and Stark 2010, 2013; Neal et al. 2015; Dupoyet, Jiang, and Zhang 2016, among others).

As to theoretical interpretations of the interest rate - credit spread relationship, among the cornerstone studies in this field, we mention the Merton (1974) structural model, which implies a negative response of credit spreads to interest rates, i.e. it means that the probability of default is affected by changes in the interest rate. We also cite the other side of the theoretical divide that advocates a positive relationship between changes in yield spreads and changes in the risk-free rate (see Kamin and von Kleist 1999). This Merton (1974) versus Kamin and von Kleist (1999) controversy attracts our attention from both the theoretical and empirical points of view, as there is substantial empirical evidence fitting each of the models. So, we undertake further research seeking to solve the above controversy.

In respect to research focused on the empirical side of the problem, we emphasize the works of Davies (2008), Boulkeroua and Stark (2010, 2013), Neal et al. (2015), and Dupoyet, Jiang, and Zhang (2016). It is worth noting that research in this field has been mostly focusing on the U.S. domestic bond market. In respect to non-U.S. markets, we would like to mention the already cited study of the evolution and determinants of Emerging Markets (EM) credit spreads performed Kamin and von Kleist (1999) and the previously cited research of Manzoni (2002). As such studies are rather rare, additional research into non-U.S. corporate is highly desirable.

The motivation of the present paper is twofold. On the one hand, there is a vast and growing literature on EM corporate bonds, which analyses tendencies and determinants of development of corporate debt markets in the EM economies (see, for example, Spiegel 2012; Mizen and Tsoukas 2014; Didier and Schmukler 2015; Tendulkar 2015; Alfaro et al. 2017; Ayala, Nedeljkovic, and Saborowski 2017; Teplova and Sokolova 2017; and references therein). In this sense, we are motivated to contribute to empirical research on the joint dynamics of the IR risk of the risk-free U.S. Treasuries and the risky EM corporate bonds. We believe this topic is especially important from the point of view of right balance between the fueling economic growth through bond market developments and the enhancement of financial stability in developing countries. 
On the other hand, we aim to shed light on the economic nature of differences in the IR sensitivity of EM corporate bonds along phases of the business cycle. Most of our motivations target linkages between the IR sensitivity to global macro drivers, as it potentially allows disentangling effects of global cycling factors and provides insights into the structural vulnerabilities in fundamentals of the corporate issuers in developing economies.

Focusing on asset price-wise sensitivity of EM portfolios, we advance empirical research of the joint risk-free U.S. Treasury (UST) bonds and risky EM corporate bonds performance. We analyze the IR sensitivity as a price sensitivity of risky EM corporates portfolios to changes in prices of the risk-free UST bonds portfolios, as the risk-free interest rates are defined by the U.S. government securities' prices. This work also contributes to the research on interdependence between credit risk, IR risk, and liquidity risk, being related to downside risk management and financial stability improvement (see Gubareva 2014; Gubareva and Borges 2014; Gubareva and Borges 2016, 2017).

This research aims to answer the following main question: does it make sense to hedge interest risk of USD-denominated EM corporate debt by short positions in the UST bonds or by pay-fixed receive-float interest rate swaps? The answer to this question is of particular importance for IR risk management, and for dimensioning economic capital to allocate for mitigating this IR risk. So, our research is potentially important for academia community, financial industry players, and regulatory bodies.

This paper is structured as follows. Section 2 describes the data and details the scope of our studies. Section 3 introduces the methodology and assumptions developed for analyses of P\&L volatility. Section 4 presents empirical results. Section 5 provides discussions and illustrations of the implications of the obtained results, and Section 6 offers concluding remarks.

\section{Empirical data and scope}

As we are interested in aggregate IR hedge techniques at a portfolio level and not on an individual asset basis, we opt to study capital gain-wise sensitivity of modeled EM bond portfolios based on yield indices describing EM corporate debt performance. After careful study of existing indices, we decide to use the two J.P. Morgan Corporate Emerging Market Bond Indices: the Broad High Grade Blended Yield (Bloomberg ticker JBBYIGIG) and the Broad High Yield Blended Yield (Bloomberg ticker JBBYNOIG).

These two blended yield indices are rule-based indices engineered to measure performance of USD-denominated fixed-rate corporate bonds of EM issuers, as defined by J.P. Morgan. These indices are computed using quite a widespread universe of EM corporate debt. Over 400 corporate bonds issued by over 200 issuers, from over forty EM countries, contribute to the each blended yield index calculations.

These two indices provide more than 14-year long historical yield series, starting on 31 December 2001, which represent a considerable time interval for studying EM debt performance in the twenty-first century. In our research, the final date of analyzed data is 31 December 2015. For analyzing a price dynamics of EM debt portfolios, the price index would perhaps be a better choice, but to the best of our knowledge no price indexes with similar issuer, geography, and historic coverage are available in the market. Thus, instead of researching individual bond price histories and/or developing a range of bond price indexes from a selected universe of individual bonds data, we opt for using the two above-mentioned yield indices to measure EM IG and EM HY corporate debt performance. 
We focus on time dynamics of assets' present value. Hence, we rule out total return indices, as the reinvestment of the net interest income proceeds does not enter our scope.

Being interested in the price dynamics of modeled portfolios hedged against IR risk, we model the basic IR risk hedging as holding short positions in UST with the five-year maturity similar to the maturity of the above-mentioned blended yield indexes. To describe the price dynamics of the IR risk hedge positions, we employ the U.S. Global Generic yield index available through the Bloomberg terminal under the USGG5YR ticker.

Wrapping up this section, it is worth highlighting the main advantages of the data-set used in the present study. We believe that one of the most important features is the outreach of the data-set geographic coverage comprising over 40 EM economies, which allows for canceling out many of idiosyncratic factors of stand-alone countries and treating EM debt as an asset class as a whole.

Additionally, each of EM IG and EM HY indices contains among the constituent instruments a large number, over 400, of bonds issued by more than 200 issuers. This certifies the broad scope of the data, inclusively in a sense of economic activity sectors, to which the obligors pertain and reduce the influence of specific risks subjacent to individual issuers and respective economic sectors dynamics.

And last, but not least, the usage in the present research of the two EM indices, i.e. EM IG and EM HY, permits to discriminate between two important debt classes, namely investment grade debt and high yield debt, and analyzes their sensitivity to interest rate risk in a separate manner.

The next section describes the methodology allowing for comprehensive analysis of EM corporate bond portfolios based on the time series of the blended yield indexes.

\section{Methodology}

The basis element of our index yield-based framework is a conversion of the available index value of the blended yield into the average price of the modeled portfolios, namely IG and HY portfolio.

First, we present an example with just one bond. Considering a 5-year bond with annual coupon $c$ and face value $p$, the price $P$ of this bond could be written as

$$
P=\frac{c}{1+y}+\frac{c}{(1+y)^{2}}+\frac{c}{(1+y)^{3}}+\frac{c}{(1+y)^{4}}+\frac{c+p}{(1+y)^{5}},
$$

where $y$ is a market interest rate for the level of riskiness associated with the bond under analyses. When the bond coupon $c$ is equal to the yield $y$, the bond is issued at par.

Now, when we have to deal with a blended yield index we do not have any actionable information on the subjacent bonds coupon values; we have just yield $y$. So, at this point, we need an assumption to overcome this lack of information, in order to find an average price of a modeled portfolio. So, we employ an assumption of a 'cruising speed' constant rate rebalancing of a portfolio. This assumption means that a bond entering the model portfolio stays in the portfolio for a certain holding period, say $n$ years, and after the end of this period the bond is sold out. We assume that all bonds in the modeled portfolio represent equal weights. Figure 1 schematically depicts the rebalancing of a model portfolio consisting of six bonds with the same face value, at any moment in time.

Any bond after an $n$-year long holding period is substituted by a newly issued on-the-run security. As the vast majority of bonds are issued at par, this gives us a key to finding an average coupon of the modeled portfolio at the date $d$ as an average of the index yield daily values 


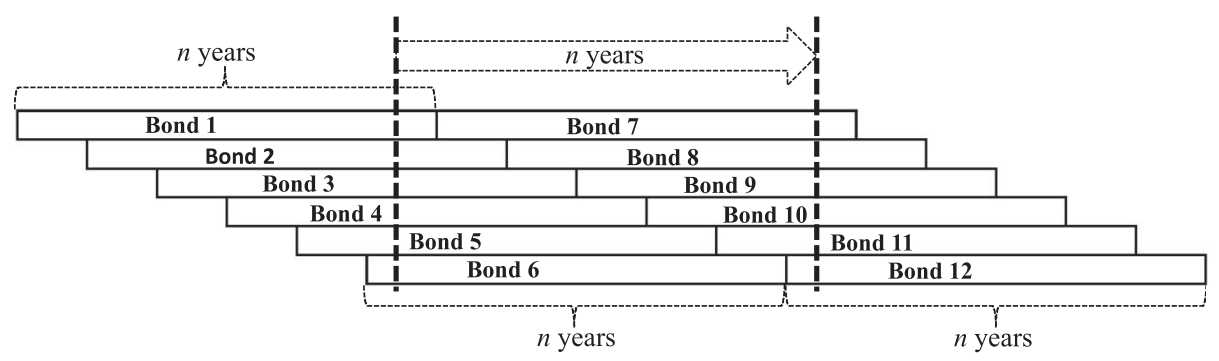

Figure 1. Schematic representation of a modeled portfolio rebalancing along $n$ years.

Note: 'Cruising speed' rebalancing of a portfolio: any bond after $n$-years spent in the portfolio is substituted by a newly issued on-the-run security.

observed over the $n$ years prior to this date $d$.

$$
c=\frac{1}{n * 365} \sum_{i=1}^{n * 365} y_{i} .
$$

In this study, we employ three different holding periods $n$ of 1,2, and 3 years. The choice of this time intervals will be discussed in more detail, further in the text.

Our research performs modeling of the two portfolios namely, EM IG and EM HY portfolios, as described by the JBBYIGIG and JBBYNOIG indices, respectively. So, we are able to price each of these two model portfolios at any date covered by the employed JBBYIGIG and JBBYNOIG historical series. For the 1-year holding period, the time window of reconstructed portfolio prices is 2003-2015, for the 2-year holding period the time window is 2004-2013, and for the 3-year holding period the time window is 2005-2015. In order to calculate the average coupon for a chosen portfolio, the appropriate rebalancing speed must be chosen. In other words, the time extension of the averaging window is to be set equal to the length of the holding period.

The possibility to have historical price series for the two EM IG and EM HY model portfolios enables us to quantify the portfolios' price variations over any chosen period of time as the difference between portfolio prices subjacent to the two chosen dates:

$$
\Delta_{P_{-} E M}(t, H)=P_{E M}(t+H)-P_{E M}(t),
$$

where $H$ stands for a time horizon over which the impact in price is analyzed.

The same approach is also applied for analyzing capital gains and losses of the short positions in UST performing the role of hedge instruments while the performance of the interest rate hedged EM portfolios is studied. So, for the long positions in UST we have:

$$
\Delta_{P_{-} U S T_{-} L O N G}(t, H)=P_{U S T_{-} L O N G}(t+H)-P_{U S T \_L O N G}(t) .
$$

For short positions, we invert the signs in the right-hand side of Equation (4):

$$
\Delta_{P_{-} U S T_{-} S H O R T}(t, H)=P_{U S T_{\text {LONG }}}(t)-P_{U S T_{-} L O N G}(t+H) .
$$

Additionally, being interested in average capital gains over rather extended time intervals, as a metrics of portfolio performance from the point of view of capital gains, we use an average 
impact in price over the available window of historic price deltas:

$$
<\Delta_{P}(t, H)>=\underset{t}{\text { Average }} \Delta_{P}(t, H) .
$$

We also analyze the aggregate performance of the EM IG and EM HY portfolios, interest rate capital gain-wise sensitivity of assets, the efficiency of hedge, downside risk exposures of hedged and unhedged portfolios as well as the respective upsides.

We define the downside risk of the portfolio as the most negative move in the price of the portfolio. We compute these metrics for both hedged and unhedged portfolios.

$$
\text { Downside }=\min _{t} \Delta_{P}(t, H),
$$

while we define the upside as a maximum gain over an analyzed period:

$$
\text { Upside }=\max _{t} \Delta_{P}(t, H) .
$$

The meaning of all these metrics is discussed in more detail in the next sections.

\section{Empirical results}

\subsection{Modeled portfolio prices}

In this subsection, we present the historic price series generated for the model portfolios with 1, 2, and 3 years. By construction, the length of such intervals is equal to the span of the time windows, along which the modeled portfolio is completely renewed, i.e. rebalanced. We consider the face value of the portfolio to be equal to 1000 million USD. Figure 2 depicts the price dynamics of the three EM IG bond portfolios with the respective bond holding periods equal to the discussed above time windows.

The three price plots appear to be quite similar prior to the apogee of the global financial crisis at the end of 2008 and also during the last three years. But during the recovery phase, one could

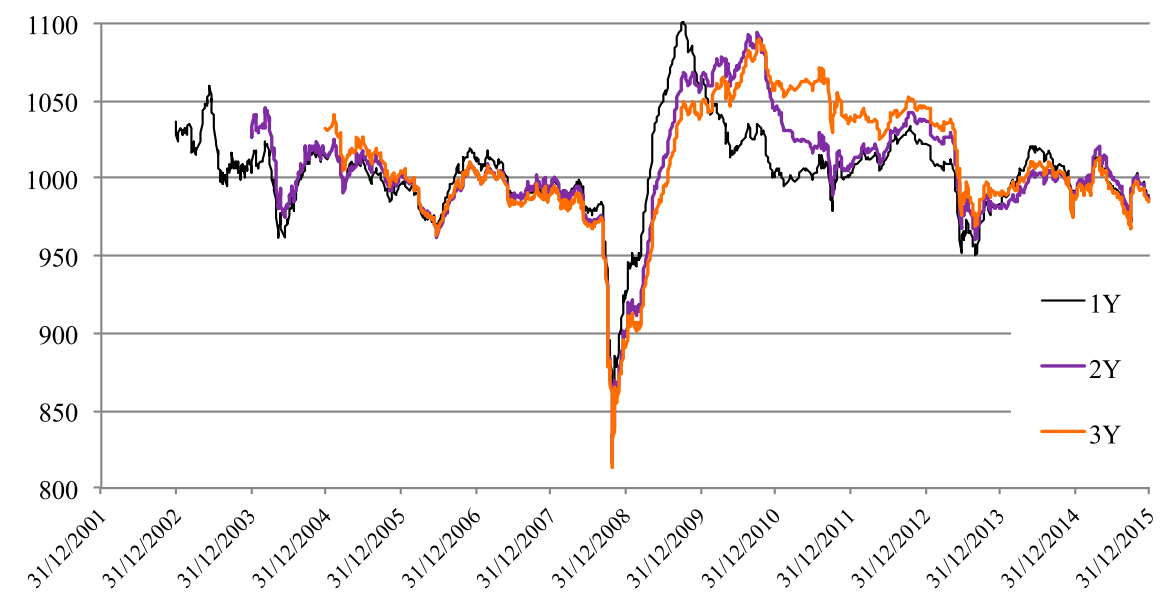

Figure 2. Prices of the EM IG bond portfolios with different bond holding periods.

Note: The plotted lines depict EM IG bond portfolio present value dynamics for 1-, 2-, and 3-year long bond holding periods. 


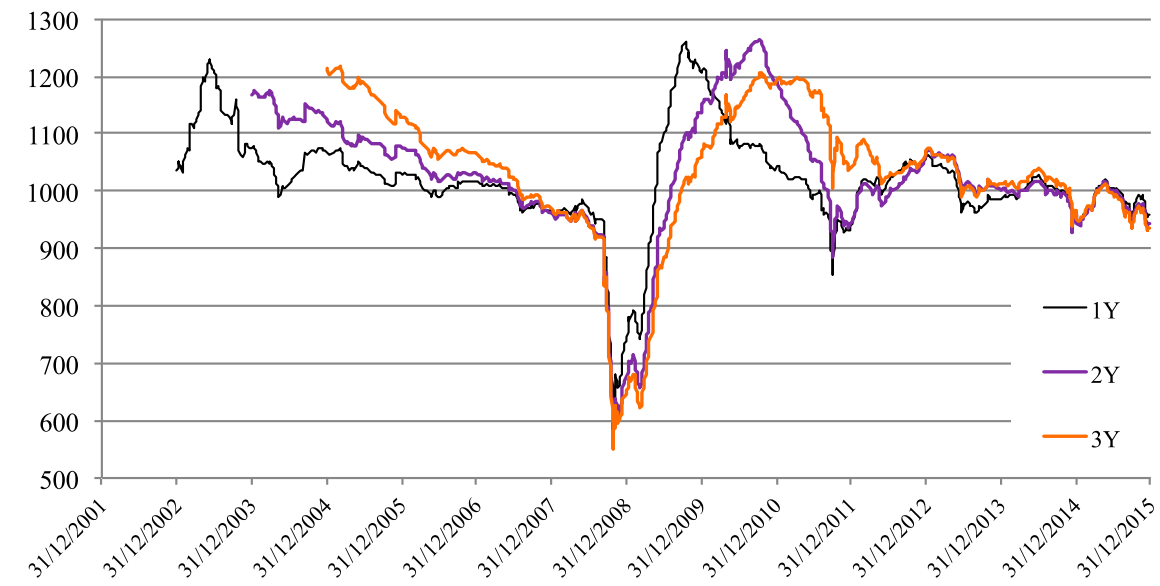

Figure 3. Prices of the EM HY bond portfolios with different bond holding periods.

Note: The plotted lines depict EM HY bond portfolio present value dynamics for 1-, 2-, and 3-year long bond holding periods.

observe major differences in the price behaviors. The major upside in prices of the portfolio subject to 1-year rebalancing occurs within 1 year after the bottom is reached. For the portfolios with the bond holding periods of 2 and 3 years, the recovery spikes are not so sharp, occurring over the respective 2 - to 3 -year long periods.

Figure 3 shows the price dynamics of the three EM HY bond portfolios with bond holding periods of 1,2 , and 3 years.

These plots of the EM HY bond portfolio prices corroborate our conclusions regarding the price recovery dynamics as a function of the bond holding period, as in Figure 2. As expected, we evidence that the impact of the recent financial crisis on EM HY portfolio prices is stronger than on the price dynamics of the IG portfolios.

Figure 4 depicts the price dynamics of the three UST long portfolios with holding periods equal to 1,2 , and 3 years.

Comparing the price behavior of the risk-free UST portfolios and the risky EM portfolios, we conclude that the global financial crises represented a huge flight-to-quality event when the prices of safe assets increased and the prices of risky EM bonds decreased. On the other hand, the range of UST price changes (roughly $-5 \% /+15 \%$, see Figure 4 ) is narrower than the range of price changes for both the EM IG corporate bonds (roughly $-20 \% /+10 \%$, see Figure 2 ) and EM HY corporate bonds (roughly $-40 \% /+20 \%$, see Figure 3 ).

\subsection{Modeled capital gains}

In this section, we study the dynamics of the historical series of the annual capital gains for the EM and UST bond portfolios. The capital gain time series are generated on a daily basis. Taken together, these data allow for generating the capital gain time series for the EM portfolios hedged by the short positions in the UST.

\subsubsection{EM IG corporate bond portfolios}

Figure 5 shows the time behavior of the annual capital gains of the EM IG corporate bond portfolio and of the risk-free UST bond portfolio. 


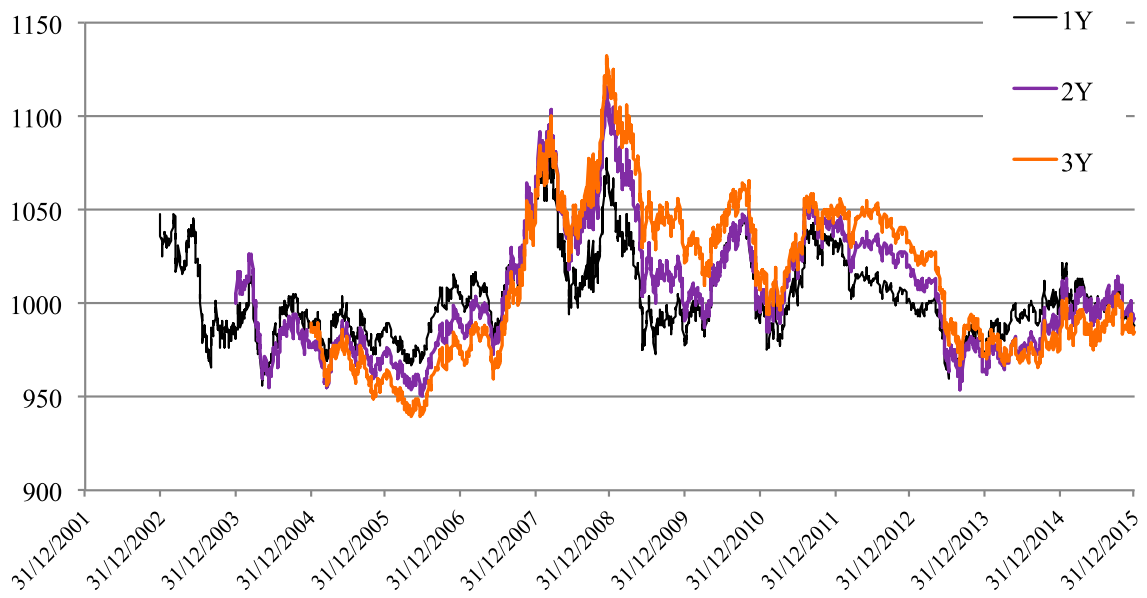

Figure 4. Prices of the UST long portfolios with different bond holding periods.

Note: The plotted lines depict UST bond portfolio present value dynamics for 1-, 2-, and 3-year long bond holding periods.

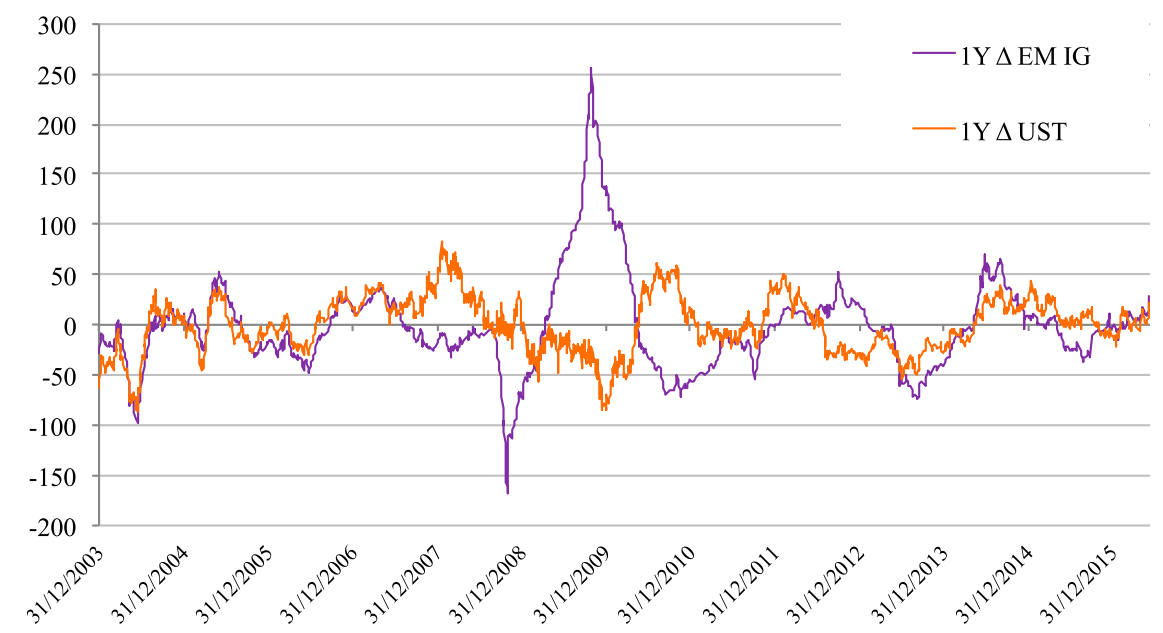

Figure 5. Annual capital gains of the EM IG and UST portfolios with 1-year rebalancing.

Note: Annual capital gains of the EM IG portfolio are plotted against annual capital gains of the UST bond portfolio: two distinct modes of joint behavior are observed along the analyzed period.

In this chart, the two points plotted for 31 December 2003 represent the respective price changes of the EM IG and UST portfolios occurred over the 1-year period started 31 December 2002. During the 2007-2012 turmoil years, prior and after the apogee of the global financial crisis, the capital gains behave in opposite modes for the two portfolios.

Hence, under the above-mentioned assumptions regarding the portfolio strategy, i.e. 1-year long horizon to measure capital gains and 1-year long stay of the bonds in the portfolio, the hedging of the EM IG portfolio with the short UST positions do not compensate the negative impacts, during the periods when such setoff is most needed. 


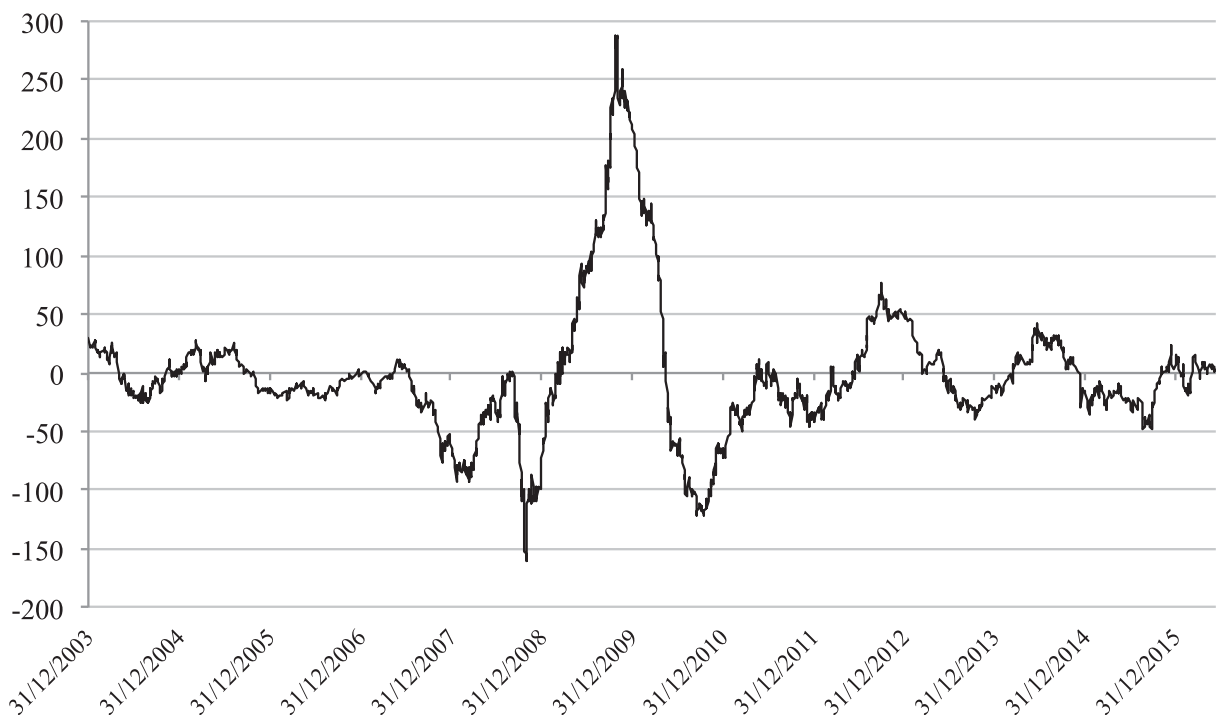

Figure 6. Annual capital gains of the EM IG long plus UST short portfolio.

Note: Annual capital gains of the EM IG portfolio hedged by the short positions in UST: the negative spikes, especially one by the end of 2008 , mean that the hedge does not work when it is the most needed.

Figure 6 shows the time behavior of the annual capital gains for the modeled EM IG corporate bond portfolio hedged by the short positions in UST bonds.

As we can see by comparing Figures 5 and 6, the observed range of the annual capital gains of the EM IG bond portfolio hedged by short positions in UST is wider than the range of the annual capital gains of the non-hedged portfolio.

Table 1 provides the comparative analysis of upside and downside risk in the modeled EM IG portfolios of 1000 million USD, observed over the available price change window for diverse rebalancing rates and the time horizon used to quantify capital gains.

Table 1. EM IG portfolios upsides and downsides for diverse bond holding periods and portfolio impact horizons.

\begin{tabular}{lccccccc}
\hline $\begin{array}{l}\text { Bond } \\
\text { holding } \\
\text { period }\end{array}$ & $\begin{array}{c}\text { Portfolio } \\
\text { impact } \\
\text { horizon }\end{array}$ & $\begin{array}{c}\text { Available } \\
\text { price } \\
\text { history } \\
\text { window }\end{array}$ & $\begin{array}{c}\text { Available } \\
\text { window } \\
\text { of price } \\
\text { changes }\end{array}$ & $\begin{array}{c}\text { EM IG } \\
\text { max } \\
\text { downside }\end{array}$ & $\begin{array}{c}\text { UST short }+ \\
\text { EM IG max } \\
\text { downside }\end{array}$ & $\begin{array}{c}\text { EM IG } \\
\text { max } \\
\text { upside }\end{array}$ & $\begin{array}{c}\text { UST short }+ \\
\text { EM IG max } \\
\text { upside }\end{array}$ \\
\hline $1 Y$ & $1 Y$ & $2003-2015$ & $2004-2015$ & $-167,85$ & $-160,46$ & 256,24 & 287,26 \\
$2 Y$ & $1 Y$ & $2004-2015$ & $2005-2015$ & $-184,47$ & $-209,07$ & 245,20 & 283,22 \\
$2 Y$ & $2 Y$ & $2004-2015$ & $2006-2015$ & $-182,52$ & $-248,31$ & 264,64 & 272,48 \\
$3 Y$ & $1 Y$ & $2005-2015$ & $2006-2015$ & $-180,79$ & $-230,29$ & 228,31 & 254,94 \\
$3 Y$ & $2 Y$ & $2005-2015$ & $2007-2015$ & $-188,31$ & $-278,39$ & 267,66 & 288,34 \\
$3 Y$ & $3 Y$ & $2005-2015$ & $2008-2015$ & $-185,93$ & $-297,64$ & 239,38 & 266,04 \\
\hline
\end{tabular}

Note: The maximum upsides/downsides in capital gains of the unhedged and hedged EM IG portfolios differ considerably; the data evidence that short positions in UST augment volatility of returns; the maximum upsides/downsides are estimated as the major positive/negative price changes for the whole eligible set of the chosen 'Portfolio Impact Horizon' intervals, i.e. the arrays of the price gauging timeframes whose final dates are contained within the 'Available window of price changes'. 
Table 2. Average capital gain-wise returns for long EM IG, long UST, and hedged long EM IG short UST portfolios for diverse bond holding periods and portfolio impact horizons.

\begin{tabular}{lcccccc}
\hline $\begin{array}{l}\text { Bond } \\
\text { holding } \\
\text { period }\end{array}$ & $\begin{array}{c}\text { Portfolio } \\
\text { impact } \\
\text { horizon }\end{array}$ & $\begin{array}{c}\text { Available } \\
\text { price } \\
\text { history } \\
\text { window }\end{array}$ & $\begin{array}{c}\text { Available } \\
\text { window of } \\
\text { price } \\
\text { changes }\end{array}$ & $\begin{array}{c}\text { Average EM } \\
\text { IG return, } \\
100 \%= \\
\text { USD 1Bi }\end{array}$ & $\begin{array}{c}\text { Average UST } \\
\text { return, 100\% } \\
\text { USD 1Bi }\end{array}$ & $\begin{array}{c}\text { Average EM IG } \\
+ \text { short UST } \\
\text { return, 100\% } \\
\text { USD 1Bi }\end{array}$ \\
\hline $1 Y$ & $1 Y$ & $2003-2015$ & $2004-2015$ & $-0.21 \%$ & $-0.06 \%$ & $-0.15 \%$ \\
$2 Y$ & $1 Y$ & $2004-2015$ & $2005-2015$ & $-0.13 \%$ & $0.10 \%$ & $-0.23 \%$ \\
$2 Y$ & $2 Y$ & $2004-2015$ & $2006-2015$ & $-0.26 \%$ & $0.15 \%$ & $-0.41 \%$ \\
$3 Y$ & $1 Y$ & $2005-2015$ & $2006-2015$ & $-0.23 \%$ & $0.20 \%$ & $-0.43 \%$ \\
$3 Y$ & $2 Y$ & $2005-2015$ & $2007-2015$ & $-0.14 \%$ & $0.42 \%$ & $-0.55 \%$ \\
$3 Y$ & $3 Y$ & $2005-2015$ & $2008-2015$ & $0.03 \%$ & $0.57 \%$ & $-054 \%$ \\
\hline
\end{tabular}

Note: Capital gain returns of EM IG portfolios are mostly negative while the capital gain returns of the UST portfolios are predominantly positive; thus, the hedge of EM IG portfolios by short positions in UST results in negative returns; this shows inefficiency of IRR hedging by short positions in UST from the point of view of securing non-negativity of capital gains; the average capital gains returns are estimated by averaging price changes over the whole eligible set of the chosen 'Portfolio Impact Horizon' intervals, i.e. the arrays of the price gauging timeframes whose final dates are contained within the 'Available window of price changes'.

As can be seen from Table 1, the difference between the lowest and the highest prices for the portfolios hedged with the hedging short UST positions is always superior to that for the unhedged portfolios. It means that, over the considered time windows, such hedge does not protect against the most extreme changes in IRR of the EM IG portfolios but rather leverage their IRR exposure. The implications of these results are addressed in Section 5.

Table 2 provides the comparative analysis of the average capital gain-wise performance of long EM IG portfolio, long UST portfolio, and the hedged long EM IG short UST portfolio for several combinations of rebalancing rate and impact horizon.

As can be seen from Table 2, the capital gain-wise returns of EM IG portfolios are slightly negative for the time windows starting in the pre-crisis years. Note that the capital gain-wise returns are not counting interim coupon payments. For the last window 2008-2015, the return becomes positive as this window mostly covers the post-crisis recovery.

The average capital gain-wise returns of the UST portfolios are predominantly positive, reflecting the fact that the variations in interest rates are largely downward since 2005. This also explains an inefficiency of IRR hedging by short positions in UST from the point the point of view of securing non-negativity of capital gains.

\subsubsection{EM HY corporate bond portfolios}

The same kind of the capital gain analysis presented in the previous section for EM IG corporate bond portfolios can be performed for the EM HY corporate bonds. Figure 7 shows the capital gains of the EM HY corporate bond portfolio and of the UST bond portfolio.

We can observe that, similarly to the EM IG case, the annual capital gains behave in an opposite mode during the years heavily impacted by the recent global financial crisis. Note that the range of changes in EM HY portfolio price is several times wider than the range of changes in the value of the risk-free UST portfolio.

So, similarly to the EM IG case, the hedging of the EM HY portfolio with the short UST positions does not seem to make any sense if one's target is to avoid downside risks. 


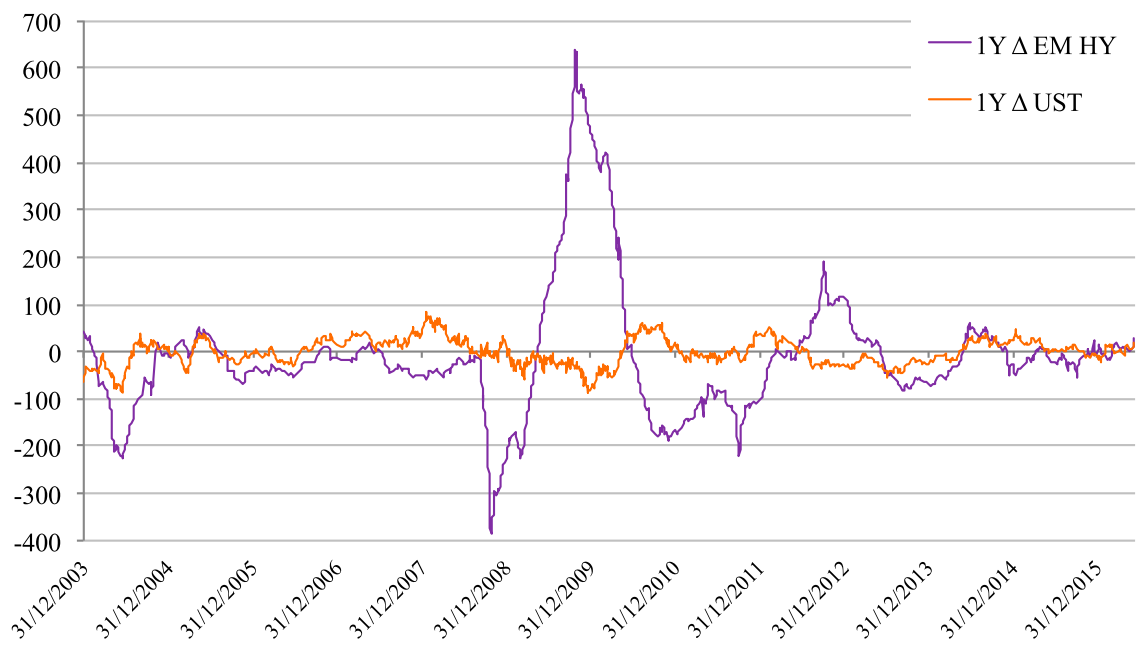

Figure 7. Annual capital gains of the EM HY and UST portfolios with 1-year rebalancing.

Note: Annual capital gains of the EM HY portfolio are plotted against annual capital gains of the UST bond portfolio: two distinct modes of joint behavior are observed along the analyzed period.

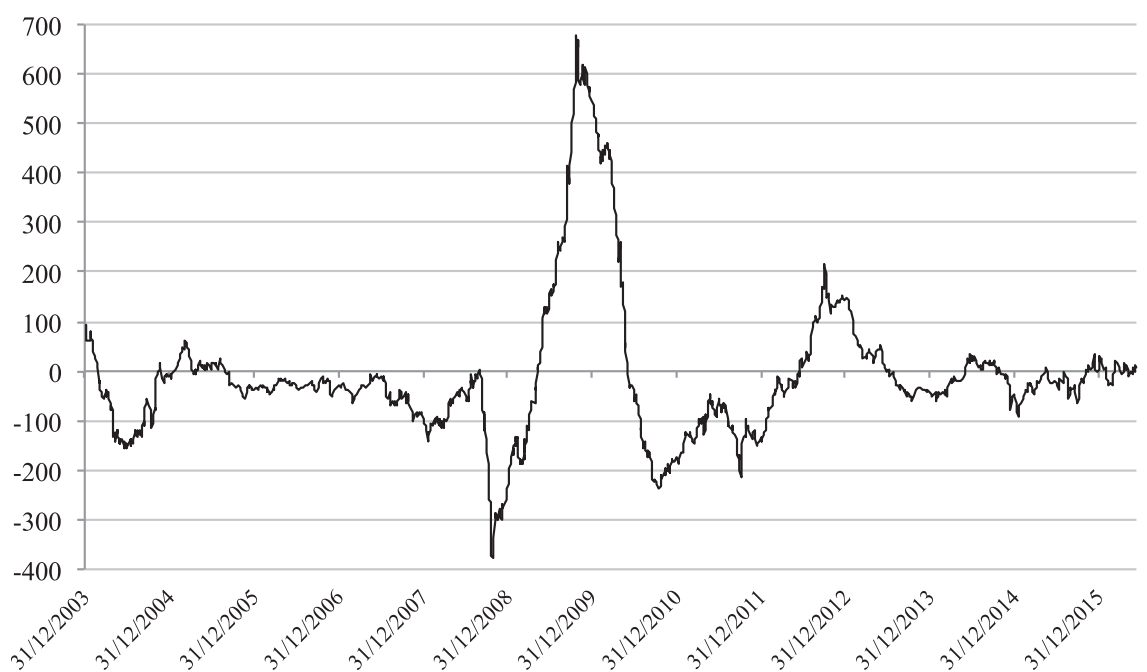

Figure 8. Annual capital gains of the EM HY long plus UST short portfolio.

Note: Annual capital gains of the EM HY portfolio hedged by the short positions in UST: the negative spikes, especially one by the end of 2008 , mean that the hedge does not work when it is the most needed.

In Figure 8, we plot the annual capital gains for the modeled EM HY corporate bond portfolio hedged 'by-the-book', i.e. by the short positions in UST bonds.

Comparing Figures 7 and 8, we see that the hedging of the EM HY bond portfolio by short positions in UST augments annual capital gains volatility instead of attenuating it.

As in the case of EM IG corporate bond portfolio, we agglutinate the modeled portfolio performance metrics in a similar format. The comparative analysis of upside and downside risk in the modeled EM HY corporate bond portfolios of 1000 million USD is presented in Table 3. As 
Table 3. EM HY portfolios upsides and downsides for diverse bond holding periods and portfolio impact horizons.

\begin{tabular}{lccccccc}
\hline $\begin{array}{l}\text { Bond } \\
\text { holding } \\
\text { period }\end{array}$ & $\begin{array}{c}\text { Portfolio } \\
\text { impact } \\
\text { horizon }\end{array}$ & $\begin{array}{c}\text { Available } \\
\text { price } \\
\text { history } \\
\text { window }\end{array}$ & $\begin{array}{c}\text { Available } \\
\text { window } \\
\text { of price } \\
\text { changes }\end{array}$ & $\begin{array}{c}\text { EM HY } \\
\text { max } \\
\text { downside }\end{array}$ & $\begin{array}{c}\text { UST short }+ \\
\text { EM HY max } \\
\text { downside }\end{array}$ & $\begin{array}{c}\text { EM HY } \\
\text { max upside }\end{array}$ & $\begin{array}{c}\text { UST short }+ \\
\text { EM Hax max } \\
\text { upside }\end{array}$ \\
\hline $1 Y$ & $1 Y$ & $2003-2015$ & $2004-2015$ & $-385,27$ & $-377,88$ & 637,58 & 677,71 \\
$2 Y$ & $1 Y$ & $2004-2015$ & $2005-2015$ & $-421,11$ & $-445,59$ & 529,87 & 602,50 \\
$2 Y$ & $2 Y$ & $2004-2015$ & $2006-2015$ & $-472,27$ & $-538,06$ & 683,39 & 695,76 \\
$3 Y$ & $1 Y$ & $2005-2015$ & $2006-2015$ & $-441,70$ & $-491,20$ & 485,97 & 559,59 \\
$3 Y$ & $2 Y$ & $2005-2015$ & $2007-2015$ & $-520,06$ & $-610,99$ & 648,14 & 664,14 \\
$3 Y$ & $3 Y$ & $2005-2015$ & $2008-2015$ & $-576,26$ & $-691,85$ & 546,30 & 572,96 \\
\hline
\end{tabular}

Note: The maximum upsides/downsides in capital gains of the unhedged and hedged EM HY portfolios differ considerably; the data evidence that short positions in UST augment volatility of returns; the maximum upsides/downsides are estimated as the major positive/negative price changes for the whole eligible set of the chosen 'Portfolio Impact Horizon' intervals, i.e. the arrays of the price gauging timeframes whose final dates are contained within the 'Available window of price changes'.

expected, these metrics depend on the bond holding period and the time horizon used to gauge present value of the portfolios.

The value gap between the lowest low, and the highest high, for the portfolios hedged with short UST positions, is always wider than such gap for the unhedged portfolios. So, shorting UST in fact does not hedge against the most extreme changes in IR, but rather leverage the effective exposure of the EM HY portfolios to IR risk. In Section 5, we will discuss the implications of these results.

The comparative analysis of the average capital gains of long EM HY portfolio, long UST portfolio, and the hedged long EM HY short UST portfolio for several combinations of portfolio rebalancing rate and portfolio impact horizon is presented in Table 4.

Table 4. Average capital gain-wise returns for long EM HY, long UST, and hedged long EM HY short UST portfolios for diverse bond holding periods and portfolio impact horizons.

\begin{tabular}{|c|c|c|c|c|c|c|}
\hline $\begin{array}{l}\text { Bond } \\
\text { holding } \\
\text { period }\end{array}$ & $\begin{array}{l}\text { Portfolio } \\
\text { impact } \\
\text { horizon }\end{array}$ & $\begin{array}{c}\text { Available } \\
\text { price history } \\
\text { window }\end{array}$ & $\begin{array}{c}\text { Available } \\
\text { window of } \\
\text { price } \\
\text { changes }\end{array}$ & $\begin{array}{c}\text { Average EM } \\
\text { HY return, } \\
100 \%= \\
\text { USD } 1 \mathrm{Bi}\end{array}$ & $\begin{array}{l}\text { Average UST } \\
\text { return, 100\% = } \\
\text { USD 1Bi }\end{array}$ & $\begin{array}{c}\text { Average EM } \\
\text { HY + short } \\
\text { UST return, } \\
100 \%=\text { USD } \\
1 \mathrm{Bi}\end{array}$ \\
\hline $1 Y$ & $1 Y$ & $2003-2015$ & 2004-2015 & $-1.19 \%$ & $-0.06 \%$ & $-1.12 \%$ \\
\hline $2 Y$ & $1 Y$ & 2004-2015 & $2005-2015$ & $-1.49 \%$ & $0.10 \%$ & $-1.59 \%$ \\
\hline $2 Y$ & $2 Y$ & $2004-2015$ & 2006-2015 & $-2.53 \%$ & $0.15 \%$ & $-2.69 \%$ \\
\hline $3 Y$ & $1 Y$ & $2005-2015$ & 2006-2015 & $-1.99 \%$ & $0.20 \%$ & $-2.19 \%$ \\
\hline $3 Y$ & $2 Y$ & $2005-2015$ & $2007-2015$ & $-2.95 \%$ & $0.42 \%$ & $-3.37 \%$ \\
\hline $3 Y$ & $3 Y$ & $2005-2015$ & 2008-2015 & $-3.19 \%$ & $0.57 \%$ & $-3.76 \%$ \\
\hline
\end{tabular}

Note: Capital gain returns of EM HY portfolios are always negative while the capital gain returns of the UST portfolios are predominantly positive; thus, the hedge of EM HY portfolios by short positions in UST results in negative returns; this shows inefficiency of IRR hedging by short positions in UST from the point of view of securing non-negativity of capital gains; the average capital gains returns are estimated by averaging price changes over the whole eligible set of the chosen 'Portfolio Impact Horizon' intervals, i.e. the arrays of the price gauging timeframes whose final dates are contained within the 'Available window of price changes'. 
As can be seen from Table 4 for the average capital gain-wise returns of EM HY portfolios, they are considerably negative for all the presented here time windows, reflecting the fact that EM HY corporates bonds were affected more strongly by the global financial crisis than the EM IG corporates securities. Note that the capital gain-wise returns are not counting interim coupon payments.

As in Table 2, the average returns of the UST portfolios are predominantly positive, reflecting the downtrend in interest rates observed since 2005. In its turn, this also explains an inefficiency of IRR hedging by short positions in UST from the point the point of view of securing nonnegativity of capital gains.

\subsubsection{Comparing performance of EM IG and EM HY corporate bond portfolios}

It is worth performing comparative analysis of the EM IG and EM HY portfolios. Table 5 presents ranges of price volatility, computed as the highest upside minus the lowest downside in a portfolio performance observed along the available windows of price changes, for EM IG and EM HY portfolios either unhedged or hedged by UST short positions.

We clearly observe that the price volatility ranges for EM IG portfolios are more than two times narrower than those for EM HY portfolios. Thus, for the case of EM, our results explicitly attest that the capital gains of EM HY portfolios are much more volatile than the capital gains of EM IG portfolios. The capital gains do not count interim coupon payments.

Table 6 summarizes statistics for the average capital gain-wise returns of the unhedged EM IG, EM HY, and UST portfolios for diverse bond holding periods and portfolio impact horizons. The last two columns on the right-hand side of the table present the average capital gain-wise returns of EM IG and EM HY portfolios, respectively, being both hedged by short positions in UST.

For the EM HY portfolios, the average capital gains for the observed windows of price changes are considerably lower than the average capital gains for EM IG portfolios. This is an expected result as the EM HY corporate bonds were supposed to be much more affected by the global financial crisis than the EM IG corporates. Still, it is important to note that the capital gains do not incorporate a part of interest income, i.e. interim coupon payments, pocketed along the time

Table 5. Price volatility ranges for EM IG and EM HY portfolios for diverse bond holding periods and portfolio impact horizons.

\begin{tabular}{lccccccc}
\hline $\begin{array}{l}\text { Bond } \\
\text { holding } \\
\text { period }\end{array}$ & $\begin{array}{c}\text { Portfolio } \\
\text { impact } \\
\text { horizon }\end{array}$ & $\begin{array}{c}\text { Available } \\
\text { price history } \\
\text { window }\end{array}$ & $\begin{array}{c}\text { Available } \\
\text { window of } \\
\text { price } \\
\text { changes }\end{array}$ & $\begin{array}{c}\text { Unhedged } \\
\text { EM IG P\&L } \\
\text { volatility } \\
\text { range }\end{array}$ & $\begin{array}{c}\text { Hedged EM } \\
\text { IG P\&L } \\
\text { volatility } \\
\text { range }\end{array}$ & $\begin{array}{c}\text { Unhedged EM } \\
\text { HY P\&L } \\
\text { volatility range }\end{array}$ & $\begin{array}{c}\text { Hedged EM } \\
\text { HY P\&L } \\
\text { volatility } \\
\text { range }\end{array}$ \\
\hline $1 Y$ & $1 Y$ & $2003-2015$ & $2004-2015$ & 424,09 & 447,72 & 1022,85 & 1055,59 \\
$2 Y$ & $1 Y$ & $2004-2015$ & $2005-2015$ & 429,67 & 492,29 & 950,99 & 1048,09 \\
$2 Y$ & $2 Y$ & $2004-2015$ & $2006-2015$ & 447,16 & 520,78 & 1155,66 & 1233,81 \\
$3 Y$ & $1 Y$ & $2005-2015$ & $2006-2015$ & 409,10 & 485,23 & 927,67 & 1050,79 \\
$3 Y$ & $2 Y$ & $2005-2015$ & $2007-2015$ & 455,97 & 566,73 & 1168,19 & 1275,14 \\
$3 Y$ & $3 Y$ & $2005-2015$ & $2008-2015$ & 425,31 & 563,68 & 1122,55 & 1264,80 \\
\hline
\end{tabular}

Note: Price volatility of EM HY portfolios is greater than the EM IG portfolio price volatility; the hedge by short positions in UST results in augmented price volatility of both EM IG and EM HY portfolios; the volatility ranges are determined by summing up the value of the major positive capital gain, or magnitude of the maximum upside, and the absolute value of the major negative capital gain, or magnitude of the maximum downside, being both estimated for the whole eligible set of the chosen 'Portfolio Impact Horizon' intervals, i.e. the arrays of the price change gauging timeframes whose final dates are contained within the 'Available window of price changes'. 
Table 6. Average capital gain-wise returns of EM IG, EM HY, and UST portfolios for diverse bond holding periods and portfolio impact horizons.

\begin{tabular}{|c|c|c|c|c|c|c|c|c|}
\hline $\begin{array}{l}\text { Bond } \\
\text { holding } \\
\text { period }\end{array}$ & $\begin{array}{c}\text { Portfolio } \\
\text { impact } \\
\text { horizon }\end{array}$ & $\begin{array}{l}\text { Available } \\
\text { price } \\
\text { history } \\
\text { window }\end{array}$ & $\begin{array}{l}\text { Available } \\
\text { window } \\
\text { of price } \\
\text { changes }\end{array}$ & $\begin{array}{l}\text { Average } \\
\text { EM IG } \\
\text { return, } \\
100 \%= \\
\text { USD } 1 \mathrm{Bi}\end{array}$ & $\begin{array}{c}\text { Average } \\
\text { EM HY } \\
\text { return, } \\
100 \%= \\
\text { USD } 1 \mathrm{Bi}\end{array}$ & $\begin{array}{c}\text { Average } \\
\text { UST } \\
\text { return, } \\
100 \%= \\
\text { USD } 1 \mathrm{Bi}\end{array}$ & $\begin{array}{c}\text { Average } \\
\text { EM IG + } \\
\text { short UST } \\
\text { return, } \\
100 \%= \\
\text { USD } 1 \mathrm{Bi}\end{array}$ & $\begin{array}{c}\text { Average } \\
\text { EM HY + } \\
\text { short UST } \\
\text { return, } \\
100 \%= \\
\text { USD } 1 \mathrm{Bi}\end{array}$ \\
\hline $1 Y$ & $1 Y$ & 2003-2015 & 2004-2015 & $-0.21 \%$ & $-1.18 \%$ & $-0.06 \%$ & $-0.15 \%$ & $-1.12 \%$ \\
\hline $2 Y$ & $1 Y$ & 2004-2015 & $2005-2015$ & $-0.13 \%$ & $-1.49 \%$ & $0.10 \%$ & $-0.23 \%$ & $-1.59 \%$ \\
\hline $2 Y$ & $2 Y$ & 2004-2015 & $2006-2015$ & $-0.26 \%$ & $-2.53 \%$ & $0.15 \%$ & $-0.41 \%$ & $-2.69 \%$ \\
\hline $3 Y$ & $1 Y$ & $2005-2015$ & $2006-2015$ & $-0.23 \%$ & $-1.99 \%$ & $0.20 \%$ & $-0.43 \%$ & $-2.19 \%$ \\
\hline $3 Y$ & $2 Y$ & $2005-2015$ & $2007-2015$ & $-0.14 \%$ & $-2.95 \%$ & $0.42 \%$ & $-0.55 \%$ & $-3.37 \%$ \\
\hline $3 Y$ & $3 Y$ & $2005-2015$ & $2008-2015$ & $0.03 \%$ & $-3.19 \%$ & $0.57 \%$ & $-0.54 \%$ & $-3.76 \%$ \\
\hline
\end{tabular}

Note: Capital gain returns of EM HY portfolios are more volatile than the capital gain returns of EM IG ones; the hedge by short positions in UST results in augmented volatility of capital gain returns for both EM IG and EM HY portfolios; the average capital gain-wise returns are estimated by averaging the portfolio price changes over the whole eligible set of the chosen 'Portfolio Impact Horizon' intervals, i.e. the arrays of the price change gauging timeframes whose final dates are contained within the 'Available window of price changes'.

windows used to gauge capital gains. As could be seen from Figures 2 and 3, the yields of EM IG and EM HY portfolios are always above $4 \%$ and $7 \%$, respectively. Thus, the respective coupons are also above these levels.

Hence, the overall average results of holding EM portfolios during the analyzed periods are positive. This is consistent with conclusions from the trends of diverse total return indexes through the time intervals under consideration; see for example J.P. Morgan EMBI Global Composite (Bloomberg ticker JPEGCOMP). Nevertheless, as we are focused on the interest rate sensitivity of assets in the sense of its impact on the present value of portfolios, we opt to abandon the interest income perspective and the total return considerations, leaving them out of the scope of our analysis.

\section{Discussions and implications}

\subsection{Binary behavior of capital gain-wise sensitivity of EM bond portfolios}

The novelty of our research resides in the fact that this study is focused on interest rate sensitivity in terms of asset prices appreciation/depreciation over rather long periods. We argue that this approach makes sense from the point of view of portfolio risk management, with the main difficulty being the absence of aggregate price data.

We overcome this difficulty by generating average prices of modeled portfolios from the available blended yield indexes, following our newly developed proprietary methodology. Fortunately, our approach permits uncovering a phenomenon of a binary behavior of pricewise interest rate sensitivity. We also propose a plausible solution to an old controversy, namely between Merton's model (Merton 1974) implying negative responses of credit spreads to interest rates, and the Kamin and von Kleist (1999) approach, resulting in non-negative responses of credit spreads to risk-free rates, each of which is reportedly supported by diverse empirical observations.

On the other hand, investigating the asset sensitivity to interest rate, from the point of view of capital gains and losses, allows us to arrive at more detailed and comprehensive conclusions. 
For example, analyzing Figure 5, one could observe two different regimes of capital gain-wise sensitivity of EM IG corporate bonds: the 'normal' regime during the periods 2004-2006 and 2013-2015 and the 'distressed' regime covering the 2007-2012 period.

Under the 'normal' regime, Figure 5 attests that the capital gains of the portfolio of EM IG corporates mimic the capital gains of the portfolio consisting of UST securities. The respective capital gain lines move closely and jointly within the 'normal' regime intervals. Within the 'distressed' regime interval, the sensitivity sign changes from positive to negative: the capital gains of risk-free and risky assets behave in opposite modes.

Another interesting aspect of the present research is the quantification of capital gain-wise sensitivity coefficients. For example, under the 'normal' pre-crisis regime of 01.01.200413.07.2007, the annual capital gains of the EM IG portfolio are related to the annual capital gains of the corresponding UST portfolio, roughly as 1 to 1 . This situation changes dramatically if we are close to the apogee of the global financial crisis. Under the 'distressed' regime, the capital gains of the EM IG portfolio are inversely related to the capital gains of the corresponding UST portfolio. The sensitivity ratio for a chosen EM portfolio equals to:

$$
S_{E M / U S T}\left(t_{2}, t_{1}\right)=\frac{A C G\left(t_{2}\right)_{E M}-A C G\left(t_{1}\right)_{E M}}{A C G\left(t_{2}\right)_{U S T}-A C G\left(t_{1}\right)_{U S T}}=\frac{\Delta A C G\left(t_{2}, t_{1}\right)_{E M}}{\Delta A C G\left(t_{2}, t_{1}\right)_{U S T}},
$$

where $S_{E M / U S T}\left(t_{2}, t_{1}\right)$ stands for a capital gain-wise sensitivity of EM corporate bonds, when the annual capital gains gauging window is moved forward on by the number of days equal to $\left(t_{2}-t_{1}\right) \cdot A C G(t)_{E M}$ and $A C G(t)_{U S T}$ stand for annual capital gains of EM bond and UST bond portfolios, respectively, while the annual capital gains gauging window ends at date $t$.

For the 'normal' pre-crisis period 01.01.2004-13.07.2007, the average capital gain-wise strength-and-length weighted sensitivities $S_{E M / U S T}$ are found to be 0.96 for both EM IG and EM HY portfolios. This means that the overall sensitivity is positive as an almost whole amount of capital gains experienced by the risk-free UST bond portfolio is passed through to the EM corporate bond portfolio, be it EM IG or EM HY. For the 'distressed' crisis period 13.07.200703.04.2013, the average capital gain-wise strength-and-length weighted sensitivities $S_{E M / U S T}$ are found to be -0.53 and -1.76 for EM IG and EM HY portfolios, respectively. This means that we observe the overall negative sensitivity, reduced in amplitude in the case of EM IG, and amplified in the case of EM HY portfolios. Such sensitivity changing from direct to inverse and back we describe by the term binary.

Back to the 'normal' post-crisis conjuncture in the period 03.04.2013-27.06.2016, the average capital gain-wise strength-and-length weighted sensitivities $S_{E M / U S T}$ are found to be 0.58 and 0.22 for EM IG and EM HY portfolios, respectively.

The exact values of the sensitivity coefficient vary depending on the portfolio choice and time intervals used for averaging. Nonetheless, for both EM IG and EM HY corporates, we evidence a phenomenon of a binary behavior of price-wise interest rate sensitivity, and hence a binary behavior of credit spread reactions to changes in risk-free interest rates.

As to the economic interpretation of the observed average sensitivity magnitudes, we posit that the differences in the sensitivities of EM IG and EM HY are related to the leverage subjacent to the types of analyzed debt. The higher the leverage, the higher is the risk, if the economy slows. Still, if the economy is under normal conditions, as in the 'normal' pre-crisis period 01.01.200413.07.2007, no worries are experienced by bond investors. Hence, there is no difference between EM IG and EM HY sensitivities, which are roughly 1 to 1 , meaning that the increase in the risk-free rates is passed through to the yield of EM instruments, either EM IG or EM HY, as the creditworthiness of issuers remains practically unaffected. 
The situation is quite different during the 'distressed' crisis period 13.07.2007-03.04.2013. For instance, for the U.S. firms the EM HY issuers leverage is higher than the leverage for EM IG firms; see, for example, S\&P Global Market Intelligence (2016). We assume that this also holds in the case of the EM.

We find sensitivity coefficients of -0.53 and -1.76 for EM IG and EM HY portfolios, respectively. In respect to the latter figure, the mean gross EM HY debt leverage averaged over the period is found to be circa 2.5 (see Quinsonas 2017). This high leverage makes all the economic sense if one takes into consideration the widely employed practice of leveraged buyouts (LBO) when an acquirer issues EM HY bonds to help pay for an acquisition and then use the target's cash flow to help pay the debt over time.

In fact, the leverage of 2.5 is consistent with the sensitivity of -1.76 , as the change magnitude of the sensitivity coefficient form 1 to -1.76 is just about 2.5 . It means that, in distress, a decrease in the risk-free interest rate is not passed through to the yield of EM HY debt, i.e. $0 \%$ is passed instead of $100 \%$ under normal conditions. Additionally, such decrease in risk-free rates augments the bond yield in circa $150 \%$ of the change magnitude due to the hardship of economic conditions negatively affecting the issuer's creditworthiness. Based on our reasoning, we estimate the EM IG gross leverage over the 'distressed' crisis period to be around 1.5 in order to result in the observed average sensitivity coefficient of -0.53 .

The return to positive sensitivity values for the new 'normal' post-crisis period for both, EM IG and EM HY debt, we ascribe to the improvement of the global economy.

\subsection{Binary sensitivities and responses of credit spreads to risk-free rates}

During the 'distressed' regime for EM HY bonds, the amplitude of the negative price-wise sensitivity is greater than the amplitude for EM IG bonds. It means that yield moves of the EM HY bonds, opposite to UST moves, are stronger than the yield moves of EM IG bonds. The EM HY bonds show more negative relation of credit spreads to interest rates than the EM IG bonds. So, regarding this subject our results corroborate with the findings of Dupoyet, Jiang, and Zhang (2016). For 1973-2014 time interval, the authors conclude that EM HY bonds show more negative relation of credit spreads to interest rates than EM IG bonds do.

On the other hand, averaging sensitivities over a long run could disguise the observable effects as spanning the window of observations over both the 'normal' market regime with positive sensitivity and the 'distressed' market regime with negative sensitivity, one could find himself observing on average only one of them, the predominant one, but damped by the other. From this point of view, our results question the meaningfulness of the findings of Dupoyet, Jiang, and Zhang (2016), which report consistent a negative relation between credit spreads and interest rates observed over the period 1973-2014.

\subsection{Solution of an old controversy: Merton's model vs. Kamin and Kleist approach}

Based on the observed binary behavior of interest rate sensitivities, we decide to revisit an old controversy, namely between structural Merton's model (Merton 1974), resulting in a negative relation of credit spreads to interest rates, and the Kamin and von Kleist (1999) approach, which posits that changes in risk-free interest rates are passed through to yields of risky assets with the same or even amplified magnitude. Kamin and von Kleist (1999) support their theoretical thinking by publishing their empirical findings for EM bonds. On the other hand, the negative relation of credit spreads to interest rates is observed in many recent studies (see, for example, 
Boulkeroua and Stark 2013; Neal et al. 2015; Dupoyet, Jiang, and Zhang 2016). These empirical studies corroborate Merton's model.

For both, the 'normal' regime (01.01.2004-13.07.2007 and 03.04.2013-31.12.2015) and the 'distressed' regime (13.07.2007-03.04.2013), our results evidence that for different periods different models provide a better fit with our empirical findings. For the 'normal' pre-crisis period, the capital gain-wise sensitivity for both EM IG and EM HY portfolios equals roughly 1 to 1 . Thus, this is consistent with the theoretical thinking of Kamin and von Kleist (1999), as it predicts mostly positive responses of credit spreads to risk-free interest rates, and posits that the probability of default is not affected by changes in the risk-free interest rate, which we believe is true for normal economic conditions.

On the contrary, for the 'distressed' regime (13.07.2007-03.04.2013), negative sensitivity values are observed for both EM IG and EM HY corporate debt portfolios. This result is clearly in line with Merton's model, which implies a negative response of credit spreads to interest rates, i.e. it means that the probability of default is affected by changes in the risk-free interest rate. This is clearly the case in times of financial turmoil. Further on, in Section 5.4, we present a theoretical explanation for the observed behavior.

The lack of consensus while interpreting empirical data could be understood through uncovering once again perils of long-run averaging. We posit that different historical spans of the time windows used during empirical studies could be responsible for apparently contrasting outcomes. Figure 9 provides a conceptual illustration of this point in terms of yields and spreads behavior.

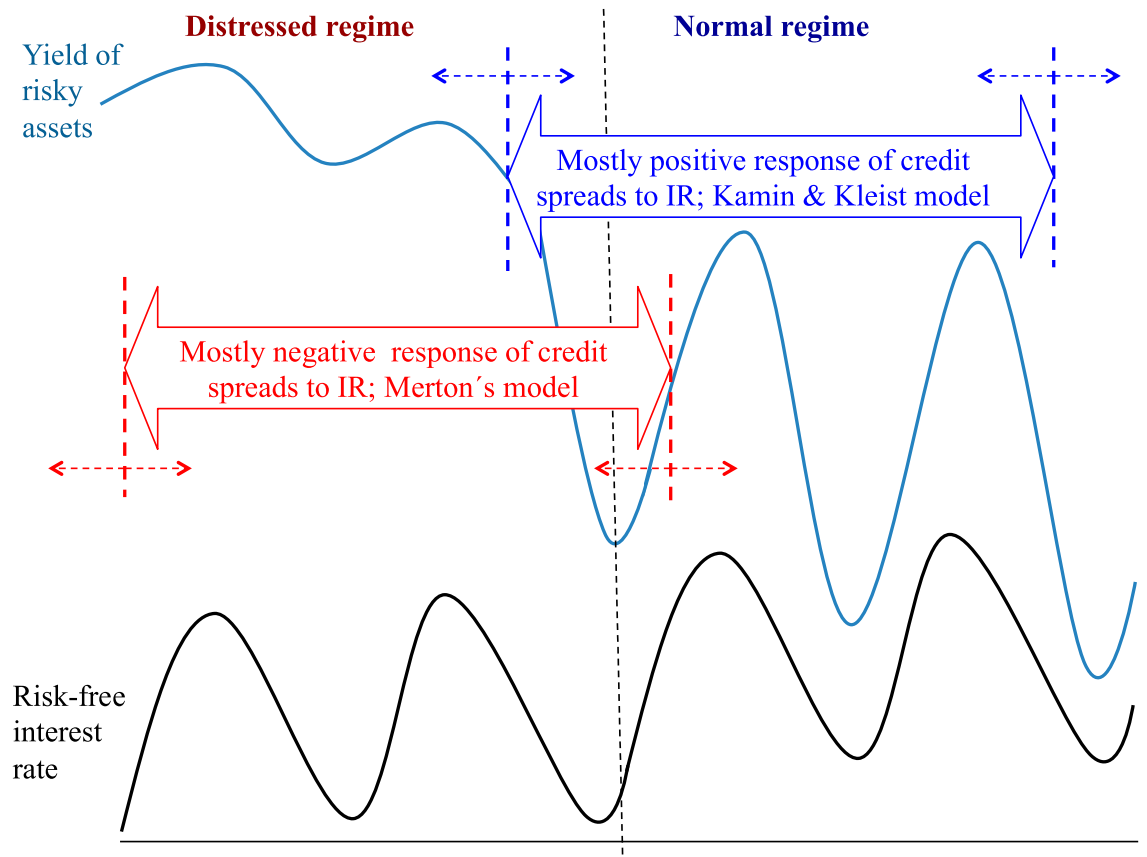

Figure 9. Negative and positive responses of credit spread to interest rate under distressed and normal regimes, respectively.

Note: Although under the distressed regime the spreads are bigger than under the normal regime, the distressed regime spreads diminish when risk-free rates increase while the normal regime spreads widen in response to the interest rate increases: extreme care should be taken while averaging spread behavior over a long run. 
Indeed, algorithms, which involve long-run averaging, present considerable risks to 'throw the baby out with the bathwater'. Eventually, depending on the span of the window over the two regimes one even could observe insensitivity to interest rate, meaning that on average two opposite sensitivities are dumped one by another. But, in fact, each model correctly describes what happens along the time interval of its applicability.

\subsection{Interest rate sensitivity of EM bond portfolios versus phases of business cycles}

Based on our analysis, we proposed an explanation for both positive and negative price-wise interest rate sensitivities of the EM portfolios observed along changing economic conjuncture. Under the 'normal' regime, the sensitivity of the capital gains of the EM portfolios to changes in the capital gains of the corresponding UST portfolio is positive. It means that the ups and downs in the risk-free interest rates are passed through to the respective bond yields. For both, EM IG and EM HY portfolios, we posit that moderate moves in the risk-free interest rate do not affect the level of corporate creditworthiness if considered from the operations point of view. This is especially true for the 01.01.2004-13.07.2007 period as under this 'normal' regime the capital gains of the EM portfolios are related to the capital gains of the corresponding UST portfolio roughly as 1 to 1 .

We ascribe such 'normal' regime of interest rate sensitivity to periods of sustainable moderate growth, i.e. not stimulated by non-conventional policy measures, and not fueled by any apparent boom of bubble creation resulting in practices of 'panic' buying and inflated prices of certain types of assets. Discussing geographically diversified EM portfolios, we certainly refer to global economic growth. Still, we posit that our reasoning also holds for EM IG and EM HY assets in isolated geographies selected on a regional and/or country basis.

On the other hand, negative interest rate sensitivity under the 'distressed' regime we ascribe to both, profound deterioration and following recovery of economic conditions, e.g. the recent crisis development and recuperation from the crisis low. 'Distressed' regime is a passage through a burst of a bubble, to the bottom and then through a recovery back to economy as usual.

During the vicious cycle of a recession, markets enter into the risk-off mode and the risk-free rate behavior exhibit a downtrend dynamics due to the increasing demand for the safe assets. Additionally, central banks in a recession adopt a policy of reducing interest rates in order to stimulate the investment. In parallel, the worsening of economy augments the credit risk of the corporates through several mechanisms. From an operations point of view, business conditions in recession get worse due to the lower demand for product and services, as uncertainty increases. Deteriorating economic conditions make it difficult for companies to obtain external investment. Financing costs keep growing. The increase in default risk, caused by the above-mentioned factors, results in the widening of credit spreads for corporate bonds while interest rates continue to drop. Thus, the risk-off mode sensitivity, i.e. flight-to-quality mode sensitivity, is negative.

During the recovery from a flight-to-quality, markets enter into the risk-on mode. In such periods, the demand for the safe assets decreases, causing the risk-free interest rate to increase. The likelihood that central banks may initiate tightening of monetary policy by increasing interest rates keeps growing, as it may become necessary to keep inflation under control. Simultaneously, this economic recovery reduces the frequency of corporate defaults. From an operations point of view, corporations start to benefit from improved consumer confidence, augmented demand, and reduced uncertainty. Financing risk and costs also decrease. As a result, the credit premia are declining while the risk-free interest rates keep increasing. The risk-on mode sensitivity is also negative, as in case of risk-off mode. 
So, only for the 'distressed' regime, to which we attribute pre-recession and post-recession phases of business cycles, our research is in line with results of Dupoyet, Jiang, and Zhang (2016), which state that the average change in interest rates (credit spreads) is negative (positive) during periods of recession while the average change in interest rates (credit spreads) is positive (negative) during periods of economic expansion. But, we claim that the periods of economic expansion referred in the cited research seem to be rather the periods of recovery from economic cycle lows than the periods of sustainable growth. We evidence and state that the negative relations between interest rates and credit spreads turn to positive under the 'normal' regime which we ascribed to the period of moderate sustainable growth present in any business cycle after the recovery from the preceding recession but prior to a bust leading to the next downturn.

\subsection{Additional considerations}

As we have evidenced by our results, it makes economic sense to hedge interest risk of USDdenominated EM corporate debt by short positions in UST bonds only over the periods of moderate sustainable growth. On the contrary, to hedge against downside risk in times of economic turmoil, as suggested by our findings, it is advisable to augment exposure to IRR, for example, by contracting pay-float receive fixed IRS. In sum, we argue that the hedging of IRR and downside risk should not be mechanical, but ought to be a dynamic process linked to phases of business cycles.

\section{Conclusions}

In this research, we develop the framework to assess an interest rate sensitivity of corporate bond portfolios based on blended yield indices. We apply our model approach to two types of EM corporates: EM IG and EM HY securities. Our research advances well beyond the widely performed studies of the relation between interest rates and credit spreads, as we investigate the impact on the present value of the modeled portfolios. We address interest risk sensitivity from the point of view of capital gains, and thus the investment horizons modeled herein vary between one and three years. Our quantification of sensitivities is quite meaningful for the interest rate risk hedging and downside risk management.

We have evidenced a phenomenon of a binary behavior of interest rate sensitivity along phases of business cycles. Under the 'normal' pre-crisis and post-crisis regimes, which we ascribe to periods of a moderate sustainable growth, the changes in the present value of EM portfolios are positively related to changes in present values of UST bonds. The sensitivity is positive. On the other hand, under the 'distressed' through-the-crisis regime, which we ascribe to the phases spanned over an entry to and exit from a recession, the changes in the present value of EM portfolios are negatively related to the changes in present values of UST bonds. The sensitivity is negative. This suggests that the downside risk hedging ought to be a dynamic process linked to phases of business cycles.

Our approach addresses the old controversy between Merton's (1974) structural model advocating the influence of interest rate on creditworthiness of obligors and the Kamin and von Kleist (1999) approach, arguing that changes in the risk-free rates are passed through to the yields of risky assets. We demonstrate that for the phases of a moderate sustainable growth the sensitivity is positive and that the latter approach fits better our empirical observations while during the distressed conditions the Merton's (1974) model provides the theoretical explanation of the 
observed negative sensitivities. Thus, the clue to the solution of this controversy resides in a binary behavior of interest rate sensitivities.

Performing numerical quantification of interest rate sensitivities along the available history of data, we detect three diverse regimes of sensitivity behavior relative to EM corporate debt, which are the 'normal' pre-crisis regime, the 'distressed' through-the-crisis' regime, and the 'normal' post-crisis regime. The respective sensitivities are the positive 1 to 1 sensitivity, the negative, i.e. inverted sensitivity, and positive but weaker sensitivity of the EM capital gains changes to the capital gains changes of UST bonds.

Examining behavior of asset sensitivity to interest rate along phases of the recent business cycles, we corroborate with our idea presented in our previous research that an integrated treatment of the IRR and credit risk potentially allows for optimizing ECAP of banks and financial institutions through improving risk assessment. Looking ahead, we can affirm that the applicability of the developed herein index-based framework to gauge interest rate sensitivity is considerably wider than the corporate debt of EM. Further research in this field is desirable for positively impacting efficiency of the financial system.

\section{Disclosure statement}

No potential conflict of interest was reported by the authors.

\section{Funding}

Financial support by IPL (Instituto Politécnico de Lisboa) is gratefully acknowledged by Mariya Gubareva. This article is part of the IPL/2016/MacroModel/ISCAL and IPL/2017/MacroTools/ISCAL projects. Financial support from national funds by FCT (Fundação para a Ciência e a Tecnologia) is gratefully acknowledged by Maria Rosa Borges. This article is part of the Strategic Project: UID/ECO/00436/2013.

\section{ORCID}

Mariya Gubareva (D) http://orcid.org/0000-0001-6829-7021

Maria Rosa Borges (D) http://orcid.org/0000-0001-5340-471X

\section{References}

Alfaro, L., A. Chari, G. Asis, and U. Panizza. 2017. Lessons Unlearned? Corporate Debt in Emerging Markets. Harvard Business School WP 17-097.

Ayala, D., M. Nedeljkovic, and C. Saborowski. 2017. "What Slice of the pie? The Corporate Bond Market Boom in Emerging Economies.” Journal of Financial Stability 30: 16-35.

BCBS (Basel Committee on Banking Supervision). 2016. Interest Rate Risk in the Banking Book. http://www.bis.org

Berends, K., R. McMenamin, T. Plestis, and R. Rosen. 2013. "The Sensitivity of Life Insurance Firms to Interest Rate Changes." Federal Reserve Bank of Chicago, Economic Perspectives, 2Q/2013, 47-78.

Boulkeroua, M., and A. Stark. 2010. "Exploring the Sensitivity of Corporate Bond Yield Spreads to Changes in the Yield Curve.” SSRN Electronic Journal. doi:10.2139/ssrn.1607688.

Boulkeroua, M., and A. Stark. 2013. "On the Determinants of the Sensitivity of the Yield Spread of Corporate Bonds to Changes in the Level and Slope of the Yield Curve." In Proceedings of the IV World Finance Conference, edited by Apergis, N., 118/167.

Davies, A. 2008. "Credit Spread Determinants: An 85 Year Perspective.” Journal of Financial Markets 11: $180-197$.

Didier, T., and S. Schmukler. 2015. "Financial Development in Asia: Beyond Aggregate Indicators. In Financial Development and Cooperation in Asia and the Pacific, Pacific Trade and Development (PAFTAD) Conference Series, edited by E. Chen, and W. Dobson, 143-169. New York: Routledge. 
Dupoyet, B., X. Jiang, and Q. Zhang. 2016. “A New Take on the Relationship between Interest Rates and Credit Spreads.” Working paper of Florida International University. http://faculty.fiu.edu/ dupoyetb/credit_spreads_heteroskedast icity.pdf

Gubareva, M. 2014. Financial Instability Through the Prism of Flight-to-Quality. Germany: Lambert Academic Publishing.

Gubareva, M., and M. Borges. 2014. "Typological Classification, Diagnostics, and Measurement of Flights-To-Quality." In Proceedings of the $V$ World Finance Conference, edited by J. Vieito, 177-295.

Gubareva, M., and M. Borges. 2016. "Typology for Flight-To-Quality Episodes and Downside Risk Measurement." Applied Economics 48 (10): 835-853. doi:10.1080/00036846.2015.1088143.

Gubareva, M., and M. Borges. 2017. "Rethinking Economic Capital Management Through the Integrated Derivative-Based Treatment of Interest Rate and Credit Risk." Annals of Operations Research 1-30. doi:10.1007/s10479-017-2438-y.

Kamin, S., and K. von Kleist. 1999. "The Evolution and Determinants of Emerging Market Credit Spreads in the 1990s." Bank for International Settlements Working Paper 68, May.

Manzoni, K. 2002. "Modeling Credit Spreads.” International Review of Financial Analysis 11: 183-218.

Merton, R. C. 1974. "On the Pricing of Corporate Debt: The Risk Structure of Interest Rates.” Journal of Finance 29: 449-470.

Mizen, P., and S. Tsoukas. 2014. "What Promotes Greater Use of the Corporate Bond Market? A Study of the Issuance Behaviour of Firms in Asia." Oxford Economic Papers 66: 227-253.

Neal, R., D. Rolph, B. Dupoyet, and X. Jiang. 2015. "Interest Rates and Credit Spread Dynamics." The Journal of Derivatives 23 (1): 25-39.

Quinsonas, C. 2017. Emerging Market Corporate Bonds - Falling Default Rates and High Yields. Too Good to be True? https://www.bondvigilantes.com/blog/panoramic-outlook/emerging-market-corporate-bonds/

Spiegel, M. 2012. "Developing Asian Local Currency Bond Markets: Why and How?" In Implications of the Global Financial Crisis for Reform and Regulation in Asia, edited by Kawai, M., D. Mayes, and P. Morgan, 221-247. Cheltenham, UK: Edward Elgar.

S\&P Global Market Intelligence. 2016. Financial Risk Is Rising for Some U.S. Corporate Borrowers as Debt and Leverage Reach Record Highs. https://www.capitaliq.com/CIQDotNet/CreditResearch/RenderArticle.aspx?articleId = 1690189\&SctArtId = 397188\&from = CM\&nsl_code $=$ LIME\&sourceObjectId = 9750107\&sourceRevId = 5\&fee_ind $=$ N\&exp_date $=$ 20260809-22:09:03

Tendulkar, R. 2015. "Corporate Bond Markets: An Emerging Markets Perspective." IOSCO Stuff Working Paper SWP6/2015.

Teplova, T., and T. Sokolova 2017. "Market Development Determinants for Corporate Bonds in National Currencies: Emerging Markets Review.” Journal of East-West Business 1-31. doi:10.1080/10669868.2017.1340387. 